\title{
Epidemiological and diagnostic aspects of spontaneous miscarriage in the department of gynecology-obstetric of the university hospital of Treichville in Abidjan
}

\author{
Ignace N. Yao ${ }^{1 *}$, Jean Marc L. Dia ${ }^{1}$, Michelle M. Menin ${ }^{2}$, Mouhedeen A. Oyelade ${ }^{1}$, \\ Corneille T. Saki ${ }^{1}$, Gerard Okon ${ }^{1}$
}

\begin{abstract}
${ }^{1}$ Department of Gynecology-Obstetric of the University Hospital of Treichville, Abidjan, Côte d'Ivoire
${ }^{2}$ Department of Gynecology-Obstetric of the University Hospital of Bouake, Côte d'Ivoire
\end{abstract}

Received: 28 September 2020

Accepted: 17 November 2020

\author{
*Correspondence: \\ Dr. Ignace N. Yao, \\ E-mail: yaoignacen@yahoo.fr
}

Copyright: (c) the author(s), publisher and licensee Medip Academy. This is an open-access article distributed under the terms of the Creative Commons Attribution Non-Commercial License, which permits unrestricted non-commercial use, distribution, and reproduction in any medium, provided the original work is properly cited.

\begin{abstract}
Background: Describe the epidemiological and diagnostic of spontaneous aspects of early miscarriage in the department of the Gynecology Obsteric of Treichville University Teaching Hospital of Treichville in Abidjan.

Methods: A cross-sectional study was performed from January 2016 to March 2017 on patients received for an early miscarriage (gestational age less than 14 weeks of amenorrhea).

Results: We recorded 337 cases of miscarriage and it shows that miscarriage was frequently estimated at 58 percent. Our patients had a average age of 32.9 years, 60.4 percent of them with primary education and 48 percent are housewives. The patients were paucigestes in 46 percent and the majority of them were nulliparous (62 percent). 6 percent with history of high blood pressure; diabetes ( 3 percent) and 31 percent of patients were HIV positive. Patients had pelvic pain at the admission in (55 percent). A miscarriage appears before 10 weeks of amenorrhea (76.1 percent) of cases. Ultrasound showed ovular debris (47 percent) of patients and (55.4 percent) were chromosomal abnormalities on anatomy-pathological examination.

Conclusions: Spontaneous abortions are common and pathological examination is essential for diagnosis.
\end{abstract}

Keywords: Chromosomal abnormalities, Pregnancy, Spontaneous miscarriages

\section{INTRODUCTION}

The first-quarter miscarriage is one of the main reasons for consultation with gynecological emergencies, since it complicates 10 to $25 \%$ of pregnancies and will affect about $25 \%$ of women during their genital life. ${ }^{1,2}$

In spite of this frequency, doctors as well as patients often do not attach great importance to it, which is why there is little study devoted to it. ${ }^{3}$ The question that any doctor should ask when faced with a first miscarriage is this an ordinary accident in the woman's obstetric life or the beginning of a series of spontaneous abortions to come? The purpose of this work was to describe the epidemiological and clinical aspects of miscarriges, but more importantly, to clarify the place of anatomopathology examination in the etiological diagnosis that can enable the prevention of subsequent recurrences.

\section{METHODS}

This is a description cross-sectional study over a 15month period from January 2016 to March 2017. This was a cross-sectional descriptive study over a 15 month period from January in the gynecology-obstetrics department of the University Hospital Treichville. 


\section{Inclusion criteria}

We considered patients received during the study period in our service for an early spontaneous abortion below 14 weeks with a complete record.

\section{Exclusion criteria}

We did not retain patients admitted for post-abortion care, or who had an inoperable record. The aspiration was made in the department either manually or electrically under local or general anesthesia as appropriate.

The suction product was fixed in $10 \%$ formalin and sent within 48 hours to the pathological anatomy department of the hospital. The variables studied included epidemiological characteristics (age, management, gender, occupation, level of study, medical history), clinical characteristics (age of pregnancy, symptoms) ultrasound results and pathological anatomy of abortion products. The data collection was done using patient records, gynecology emergency admission records, patient pathology laboratory reporting records. The analysis of the data was done using the epi software info. ${ }^{6}$

\section{RESULTS}

\section{Epidemiological and socio-demographic characteristics}

During the study period, we recorded 5895 pregnancies. $337(5.7 \%)$ were spontaneous abortions, of which 197 $(58 \%)$ were early.

Table 1: Distribution of patients by sociodemographic characteristics.

\begin{tabular}{|lll|}
\hline $\begin{array}{l}\text { Socio-demographic } \\
\text { characteristics }\end{array}$ & Numbers & $\begin{array}{l}\text { Frequency } \\
\text { (percent) }\end{array}$ \\
\hline Age (in years) & 4 & 2 \\
\hline $20-24$ & 45 & 22,9 \\
\hline $25-29$ & 80 & 40,6 \\
\hline $30-34$ & 53 & 26,9 \\
\hline $35-39$ & 15 & 7,6 \\
\hline$>40$ & & \\
\hline Level of study & 119 & 60,4 \\
\hline Primary & 45 & 22,8 \\
\hline Secondary & 33 & 16,8 \\
\hline High school & & \\
\hline Marital status & 114 & 58 \\
\hline Married & 30 & 15 \\
\hline Single & 53 & 27 \\
\hline Concubating & & \\
\hline Profession & 94 & 48 \\
\hline Housewife & 36 & 18 \\
\hline Seller & 14 & 7 \\
\hline Student & 53 & 27 \\
\hline Employee & & \\
\hline
\end{tabular}

The majority of our patients were between 30 and 34 years old $(41 \%)$ and the average age was 32.9 years with extremes of 20 and 43 years. In $48 \%$ of the cases of housewives, the majority (58\%) were married.

\section{Background}

Patients had pelvic pain when admitted in $55 \%$ of cases. The CHF had occurred before 10 weeks in the majority of cases $(76.1 \%)$. Ultrasound was found to have an unwanted pregnancy in $22 \%$ of cases, ovular debris in $47 \%$ of patients, and a clear egg in $31 \%$. Manual suction in the uterine (AMIU) was the method of choice in handling with $93 \%$ of cases.

Table 2: Distribution of patients by history.

\begin{tabular}{|lll|}
\hline History & Number & Frequency (\%) \\
\hline Managed & & \\
\hline 1 & 81 & 41.1 \\
\hline $2-3$ & 90 & 45.7 \\
\hline$\geq 4$ & 26 & 13.1 \\
\hline Parity & & \\
\hline 0 & 122 & 61.9 \\
\hline 1 & 33 & 16.7 \\
\hline $2-3$ & 29 & 14.7 \\
\hline$\geq 4$ & 13 & 6.7 \\
\hline Medicals histories & & \\
\hline HTA & 12 & 6.1 \\
\hline Diabetes & 6 & 3 \\
\hline HIV & 61 & 31 \\
\hline $\begin{array}{l}\text { Spontaneous } \\
\text { miscarrage }\end{array}$ & 44 & 22.3 \\
\hline None & 74 & 37.6 \\
\hline
\end{tabular}

Patients were paucigests in $87 \%$ of cases and nulliparous in $62 \%$ of cases. $31 \%$ of patients were HIV positive and $22.3 \%$ had a history of miscarriage.

\section{Diagnostic aspects}

Table 3: Distribution of patients by clinical characteristics

\begin{tabular}{|lll|}
\hline Clinical aspect & Number & Frequency (\%) \\
\hline Reason for consultation & & \\
\hline Metrorrhages & 175 & 89 \\
\hline Pelvic pain & 108 & 55 \\
\hline Gestational age & & \\
\hline $\begin{array}{l}<10 \text { weeks (week of } \\
\text { amenorrhea) }\end{array}$ & 150 & 76,1 \\
\hline$>10-<14$ SA & 47 & 23,9 \\
\hline
\end{tabular}

Patients had pelvic pain upon admission in 55 percent of cases. Miscarriage had occurred prior to 10 weeks in the majority of cases (76.1 percent). Ultrasound showed a 22 percent termination of pregnancy, ovular debris in 47 percent of patients and a clear egg in 31 percent. 
Manual intra uterine aspiration was the method of choice in the management with 93 percent of cases. The different histological types found were chromosomal abnormalities with 55.4 percent (including 58.8 percent trisomy) and partial mole in 5.5 percent. in 39.1 percent of cases, no abnormalities were found in the histology of the abortion product.

\section{DISCUSSION}

\section{Epidemiological and socio-demographic characteristics}

Spontaneous abortions are a frequent complication of pregnancy. We observed a frequency of $5.7 \%$ of spontaneous abortions during our study period compared to births. This rate is significantly lower than the rates in the literature, which are around $15 \% .^{4-8}$ The explanation may come from the fact that several lower-level centers also handle cases of spontaneous abortions, especially when they are not complicated. Early miscarrage accounted for 58 per cent of this number. In this respect our rates are superimposed on those of Cissé in Senegal, which in its series finds a rate of $57.7 \%$ of early spontaneous abortion.

The average age of our patients was $32.9 \%$. Spontaneous abortion occurs at any age of a woman's genital life, with a predominance of miscarriages in the 30-40 age group. ${ }^{3}$ The older the woman grows, the higher the risk of spontaneous miscarriage. ${ }^{8-10}$ The majority of our patients $(85 \%)$ were married women or women living in couples. This predominance of married women is similar to those mentioned in the literature. ${ }^{12}$

\section{Background}

The medical history usually associated with spontaneous miscarriages (high blood pressure and diabetes) was rarely found in our series ( 6 percent and 3 percent). Luise found an high blood pressure record twice as high level in this series with 12 percent. ${ }^{12}$ In our series like Cissé, about one out of four patients had a history of miscarriage. $^{4}$

\section{Clinical aspects}

In our series, the main reasons for consultation are metrorrhagia (89\%) followed by pelvic pain $(55 \%)$. These two patterns are most often associated. C.T Cissé in his series in Senegal found hemorrhage as the main reason for consultation in $95 \%$ of cases. ${ }^{4}$ Malaria was the context for the occurrence of miscarrage $10.6 \%$ of patients. Frequent situation in our malaria endemic countries. The majority of False diapers occurred before 10 weeks in 76.1 percent.

The rate of ultrasound realization in our series is $48 \%$ and confirmed the FCS. The diagnosis in other cases was referred to in the perception of ovular debris in the cervical or the abortion product when the eviction occurred in the service. CT Cissé had an ultrasound realization rate of $59.7 \% .{ }^{4}$ The ultrasound to a double advantage. The procedure of specifying the type of FCS, either complete or incomplete, and allows, depending on the importance of the intrauterine content, to choose the method of intervention which can range from simple expectancies to surgical methods to medications. ${ }^{13,14}$

\section{Pathological anatomy}

The appearance of abortion products at Cissé was dominated by their trivial appearance in $85 \%$ of cases. The clear egg was only $5.8 \%$. This difference could be due to the fact that he took into account the aspect of the evacuation product in his results, while we took into account in our series the echographic result which he thought was more accurate.

Expulsion products were examined anatomically and pathologically in $47 \%$ of cases. This examination is the burden of the patients and is not available to all (30000 FCFA/47 Euro). This relatively high cost explains the lack of systematic implementation in our context. This histological examination may find a cause for preventive action to prevent recurrence. ${ }^{15}$ Chromosome abnormalities were found in $55.4 \%$ of the cases and were found in the form of an uneven-sized villosity with bubbling dystrophies. This rate of chromosomal abnormality of spontaneous miscarriages in the first quarter is consistent with the literature which estimates it between 50 and $70 \% .^{16}$ We found $5.4 \%$ partial mole. This rate is higher than that found by Luise. ${ }^{12}$ Parent karyotype was not realized in our series, certainly because of its cost. In all cases, this cytogenetic study of the abortion product and the karyotype of the parents is necessary if we want to prevent the CHF repeatedly by proposing genetic counseling to infertile couples. ${ }^{2,9}$

The absence of histological abnormality in our study accounts for nearly $40 \%$ of the cases. Infectious causes such as malaria must be mentioned in the context of fever in the first trimester of pregnancy in tropical environments. ${ }^{17}$

\section{Limitation}

The main limitation of this study is that; it is a descriptive study which does not allow us to make the correlation between the different parameters studied.

\section{CONCLUSION}

Spontaneous miscarriage are a frequent complication of pregnancy. The study of the clinic and the ultrasound of her abortion sometimes helps to understand the causes of these abortions. However, an anatomopathological examination of the design product is always necessary to confirm the etiological diagnosis in order to improve the obstetric future of the patients. 
Funding: No funding sources

Conflict of interest: None declared

Ethical approval: The study was approved by the Institutional Ethics Committee

\section{REFERENCES}

1. Blohm F, Friden B, Milson I. A prospective longitudinal population-based study of clinical miscarriage in an urban Swedish population. BJOG. 2008; 115:176-82.

2. Houmaid H, Bekkay C, Nassereddine S, Talbi H, Amehdare L, Hilali A. Chromosomal abnormalities in 238 couples with recurrent miscarriages in Morocco. Open J Genetics. 2018;8:15-22.

3. Trinder J, Brocklehurst P, Porter R, Read M, Vyas S, Smith L. Management of miscarriage: expectant, medical or surgical? Results of randomised controlled trial miscarriage treatment (MIST). BMJ. 2006;332:1235-40.

4. Cissé CT, Faye KG, Moreau JC. First trimester abortions at Dakar University Hospital: benefit of manual intrauterine aspiration. Med Trop. 2007;67:163-6.

5. Graziosi GCM, Mol BW, Ankum WM, Bruinse HW. Management of early pregnancy loss. Int J Gynecol Obstet. 2004;86:337-46.

6. Tong S, Kaur A, Walker SP, Bryant V, Onwude JL, Permezel M. Miscarriage risk for asymptomatic women after a normal first-trimester prenatal visit Obstet Gynecol. 2008;111:710-4.

7. Reeves MF, Lohr PA, Harwood BJ, Creinin MD. Ultrasonographic endometrial thickness after medical and surgical management of early pregnancy failure Obstet Gynecol. 2008;111:106-12.

8. Delabaere F. Epidemiology of pregnancy loss. J Gynecol Obstét Biol Reprod. 2014;43:764-75.

9. Lejeune V. Repeated spontaneous miscarriages: etiological assessment and management of subsequent pregnancies. J Gynecol Obstet Biol Rep. 2010;39:11-6.

10. Rai R, Regan L. Recurrent miscarriage. Lancet. 2006;368:601-11.

11. Ancel PY, Cubizolles MJ, Renzo GC, Papiernik E, Breart G. Risk factors for 14-21 week abortions: a case-control study in Europe. Hum Reprod. 2000; $15: 2426-32$.

12. Luise C, Jermy K, May C, Costello G, Collins W.P, Bourne TH. Outcome of expectant management of spontaneous first trimester miscarriage: observational study. BMJ. 2002;324:873-5.

13. Maru L, Verma M, Khan T. Reinforcing the vast difference between the outcomes of spontaneous versus induced miscarriages. Int J Reprod Contracept Obstet Gynecol. 2016;5:4031-6.

14. Blohm F, Friden B, Christensen JJ. Expectant management of first trimester miscarriage in clinical practice. Acta Obstet Gynecol Scand. 2003;82:654-8.

15. Ksouri H, Zitouni M, Achour W, Makni S, Ben Hassen A. Fetal loss and repeated spontaneous abortions of immunological origin. Ann Med Interne. 2003;154(4):233-47.

16. Stephenson MD, Awartani KA, Robinson WP. Cytogenetic analysis of miscarriages from couples with recurrent miscarriage: a case-control study. Hum Reprod. 2002;17:446-51.

17. Palem G, Pal SJ. Maternal and fetal outcome of malaria in pregnancy. Int J Reprod Contracept Obstet Gynecol. 2019;8:4040-4.

Cite this article as: Yao IN, Dia JML, Menin MM, Oyelade MA, Saki CT, Okon G. Epidemiological and diagnostic aspects of spontaneous miscarriage in the department of gynecology-obstetric of the university hospital of Treichville in Abidjan. Int J Reprod Contracept Obstet Gynecol 2021;10:1-4. 